\title{
Effectiveness of Locally Available Plant Materials in the Dry Zone of Sri Lanka as Natural Coagulants in Treating Turbid Water
}

\author{
B.A.P. Serasinghe ${ }^{1}$, N.S. Abeysingha ${ }^{1 *}$, D.M.S.H. Dissanyake ${ }^{1}$ and N.V.H.S.K. Vithanage ${ }^{2}$ \\ Received: $20^{\text {th }}$ November 2020 / Accepted: $25^{\text {th }}$ August 2021
}

\begin{abstract}
Purpose: Polyaluminium chloride (PAC) is used to treat the turbid water at water treatment plants. As an alternative, natural coagulants are being tested as those are biodegradable and safe for human health. The study focused to test the locally available five different plant species as natural coagulants.

Research Method: Turbid water samples were treated separately by 50ppm to 100ppm of PAC as a control, and powdered Moringa (Moringa oleifera), Arjun (Terminalia arjuna), Jack fruit (Artocarpus heterophyllus), Clearing nut (Strychnos potatorum L.) seeds and Aloe (Aloe vera) as treatments. Turbidity, $p H$, and EC were measured before and after the treatments. The experiments were conducted as a full nested design to test the effect of coagulant variety and concentration on the turbidity removal with a mean comparison using Turkey's Studentized Range Test at 0.05 significant level.

Findings: Moringa showed the highest turbidity removal efficiency of $84.8( \pm 8.9) \%$. Arjun and Aloe demonstrated turbidity removal efficiency of $42.6( \pm 6.71) \%$, and $34.9( \pm 6.03) \%$ respectively and it was significantly $(P<0.05)$ higher than those of Jack fruit $18.2( \pm 9.3) \%$ and Clearing nut $30.4( \pm 23.7) \%$. This study concludes that among natural coagulants tested, Moringa has the highest capability of removing the turbidity of water.
\end{abstract}

Research Limitations: Clearing nut seed powder was taken from a shop which may be of inferior quality compared to the fresh seed powder.

Originality/value: There is a higher potential to use Moringa seed collected from the dry zone as a natural coagulant.

Keywords: Moringa, Natural coagulants, Polyaluminium chloride, Turbidity, Water treatment

\section{INTRODUCTION}

Drinking water is an essential requirement of all living beings including humans for their survival. Most of the drinking water supply sources in Sri Lanka are surface water such as lakes, streams and rivers (Ravindara et al., 2013). But, the purity level of surface water is uncertain due to the concentration of various types of pollutants, the development of turbidity and colour from the colloidal impurities (Dharmasinghe, 2017) occurring through many ways particularly through anthropogenic factors that make water unsafe for consumption (Yongabi, 2010). Thus, conventional water treatment plants utilize

the process of coagulation /flocculation for the removal or the reduction of turbidity in the form of colloidal materials and suspensions (Ravindara et al., 2013) and the chemicals used for the process are called coagulants.

\footnotetext{
${ }^{I^{*}}$ Department of Agricultural Engineering and Soil Science, Faculty of Agriculture, Rajarata University of Sri Lanka, Anuradhapura, Sri Lanka. nabeysingha@gmail.com

${ }^{2}$ National Water Supply \& Drainage Board, Harishchandra Mawatha, Anuradhapura, Sri Lanka.

(D)https://orcid.org/0000-0003-4635-3285
} 
Synthetic organic and inorganic coagulants are the most commonly used chemicals for various water treatment plants (Asrafuzzaman et al., 2011). Among them, aluminium and iron-based coagulants are the most widely used coagulants for water and wastewater treatment. The most common aluminium and iron salts utilized are aluminium sulphate (alum), aluminium chloride, ferric sulphate and ferric chloride. Poly aluminium sulphate (PAS), poly aluminium silicate sulphate (PASS), poly aluminium chloride (PAC), pre-hydrolyzed alum, hydroxylated ferric sulphate, poly ferric sulphate and poly ferric chloride are the complex forms (pre hydrolyzed or pre-polymerized salts) of them (Niquette et al.,2004). But, several studies have pointed out the drawbacks when dealing with Aluminium salts (Bratby, 1980). The use of aluminium salts causes for the production of large sludge volume and has low efficiency in coagulation of cold water (Ravikumar and Sheeja, 2013). It has been found that residual aluminium based coagulants in waters link to the development of Alzheimer's disease in human (Flaten, 2001). As an alternative, several studies focused on the production of more effective trivalent aluminium coagulants such as polyaluminium chloride (PAC) and polyaluminium silico sulphate (PASS). However, these coagulants are still unable to correct all the drawbacks of aluminium salts ( Kurniawan et al., 2020).

When considering all these issues, it is confirmed that there should be a biodegradable, locally available, and healthy method for water purification process for the people who frequently use low quality drinking water. Having a long history, natural coagulants can be taken as a simple method for the water purification process. Natural coagulants which may be prepared from plant seeds, leaves, and roots have been used for more than 2000 years in India, Africa, and China as effective coagulants and coagulant aids at high water turbidities (Asrafuzzaman et al., 2011). Rural women in Sudan used dried Moringa (Moringa oleifera) seeds as a coagulant instead of Alum for removing the turbidity in Nile water (Jahn,1988). Igini (Strychnos potatorum) seed powder has been used for clearing muddy water by the rural community in India (Jayaram et al., 2009) while Aloe (Aloe vera) gel has been used in several studies as a natural coagulant for treating drinking water (Munavalli, 2017). In addition, Jack fruit seeds have also been used as a coagulant in waste water treatment in reducing the turbidity (Aneesu et al., 2018).

Sri Lanka is divided into dry, wet and intermediate climate zones and dry and intermediate zone areas are mostly suffer from water scarcity specially during the Yala (May to September) cropping season. Early inhabitants of these areas used to use surface water taken from small tanks as the main source of drinking water. This tank water is turbid particularly during the Yala season mainly due to low water levels. People in the area practiced to add Ingini (Strychnos potatorum) seeds to settle the muds and then filtered the water using a piece of cloth (Abeysingha et al., 2018). Since there are no poTable 0water supply schemes equally distributed everywhere in the dry zone, people in these areas can still use tank water with the sound tank catchment management plan and they can use even at present, natural coagulants to remove the turbidity of water. Moreover, there is a need for testing new plant species as natural coagulants which are suiTable Ofor treating turbid surface waters in dry zone of Sri Lanka. Therefore, the objective of this study was to investigate the suitability of several locally available plant materials in the dry zone such as Moringa (Moringa oleifera), Clearing nut (Strychnos potatorum), Aloe (Aloe vera), Arjun (Terminalia arjuna) and Jack fruit (Artocarpus heterophyllus) in reducing the turbidity of water.

\section{METHODOLOGY}

\section{Collection of water samples}

Water samples for the experiment were collected from the intake chamber of water treatment plant Nuwara wewa, Anuradhapura. These aerated surface water samples were collected using precleaned high density polyethylene bottles.

\section{Preparation of synthetic turbid water}

$30 \mathrm{~g}$ of clay material was collected from Nuwara Wewa and added to one liter of water collected. 
Then the water sample was stirred for one hour to achieve a uniform dispersion of clay particles and allowed to settle for 24 hours for complete hydration of the clay materials. This can be referred to as synthetic turbid water. The supernatant suspension of the synthetic turbid water was added to water samples collected to achieve the desired turbidity just before coagulation following the same methodology of Asrafuzzaman et al., 2011. Generated turbidity levels were between 65 to 150 NTU. However, for each experiment, turbidity level was measured in this synthetically prepared turbid water before the experiment.

\section{Collection and preparation of plant materials}

Arjun seeds, Jack fruit seeds and Aloe Vera, Clearing nut seed powder, Moringa seeds were collected from Anuradhapura area, dry zone of Sri Lanka. Plant extracts were prepared according to the method described by Arasaretnam and Keerthanan, (2018). Arjun fruits and Aloe Vera leaves were washed several times with distilled water. Collected plant materials were air dried at room temperature for 3 days and oven dried at $80{ }^{\circ} \mathrm{C}$ for 3 hours and ground using a kitchen blender to make similar particle sized powder. For Arjun, the powdered sample was again washed repeatedly with distilled water to remove color and dried at $60^{\circ} \mathrm{C}$ for $24 \mathrm{~h}$ in oven (Rao et al., 2016). All the plant material powders were sieved using $0.5 \mathrm{~mm}$ sieve to achieve a similar size powder. For Aloe Vera, green epidermis was removed from gel part and blended to form a liquid (Munavalli, 2017).

\section{Preparation of coagulants}

Suspensions of plant materials with $1 \%$ concentration were prepared with distilled water which was used as stock solutions for the experiment 1 . And also, Poly Aluminium Chloride (PAC) used by the laboratory of National Water Supply and Drainage Board was taken to prepare $1 \%$ PAC which was also used in experiment 1. Suspensions of plant materials with $1 \%, 2 \%, 3 \%$,
$4 \%, 5 \%$, and $6 \%$ were prepared with distilled water for the experiment 2. The suspensions were vigorously shaken for 5 minutes manually to promote water extraction of the coagulant proteins and this was then passed through filter paper (Whatman No.1, 125mm dia). The filtrate portions were used for the required dose of natural coagulant. Fresh solutions were prepared daily and kept refrigerated to prevent any ageing effects (such as changes in $\mathrm{pH}$, viscosity, and coagulation activity). Solutions were shaken vigorously before use (Asrafuzzaman et al., 2011).

\section{Jar test operation}

A convectional jar test apparatus (Stuart Scientific Flocculator SW1) was used for the experiment (Figure 01) to coagulate the water samples using the coagulants. It was carried out in a batch test accommodating six beakers with six spindle steel paddles. Water samples were mixed homogeneously before operating the jar test. Initial turbidity was measured using turbidity meter.

\section{Experiment 1}

Experiment 1 was conducted to compare the effect of natural coagulants with PAC on synthetic turbid water. For this purpose, $5 \mathrm{ml}, 6 \mathrm{ml}, 7 \mathrm{ml}, 8 \mathrm{ml}$, $9 \mathrm{ml}$, and $10 \mathrm{ml}$ volumes from each $1 \%$ prepared stock solution were added to the synthetic turbid water samples to get the final concentrations of coagulant as $50 \mathrm{mg} / \mathrm{L}, 60 \mathrm{mg} / \mathrm{L}, 70 \mathrm{mg} / \mathrm{L}, 80$ $\mathrm{mg} / \mathrm{L}, 90 \mathrm{mg} / \mathrm{L}$, and $100 \mathrm{mg} / \mathrm{L}$. Then, the beakers with these concentration of coagulant and turbid water were agitated at various mixing times and speeds, which consist of rapid mixing (180 revolutions per minutes (rpm)) for 3 minutes, $100 \mathrm{rpm}$ for 2 minutes and slow mixing (20 rpm) for 20 minutes. Thereafter, the suspensions were allowed to settle for 20 minutes. Finally, a sample was withdrawn using a pipette from the middle of the supernatant for physicochemical analysis. 


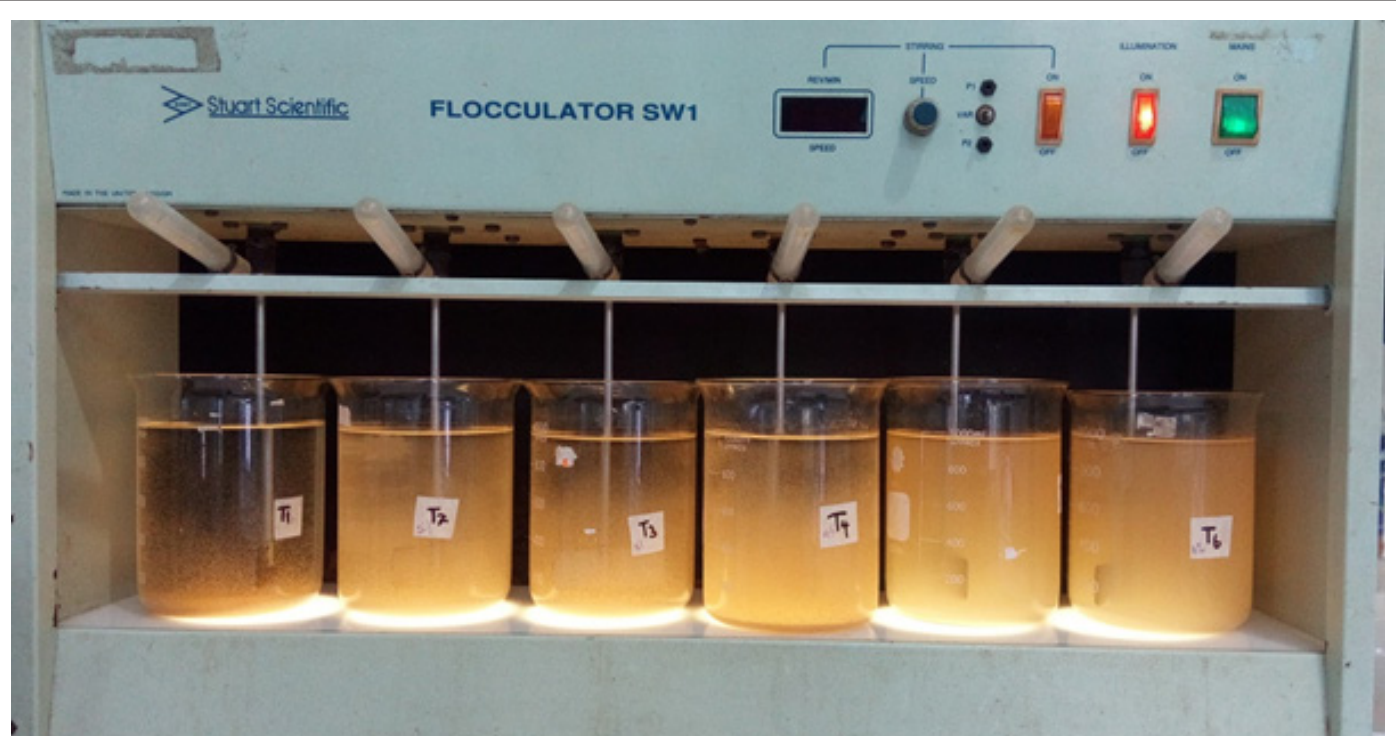

Figure 01: Apparatus for conducting Jar Test at the Laboratory

\section{Experiment 2}

To distinguish the best natural coagulant, $100 \mathrm{ml}$ of natural coagulants with varying concentrations $(1 \%, 2 \%, 3 \%, 4 \%, 5 \%$ and $6 \%)$ were added into synthetically prepared turbid water (samples of $900 \mathrm{ml}$ ) to get the final coagulant concentrations as $1000 \mathrm{mg} / \mathrm{L}, 2000 \mathrm{mg} / \mathrm{L}, 3000 \mathrm{mg} / \mathrm{L}, 4000$ $\mathrm{mg} / \mathrm{L}, 5000 \mathrm{mg} / \mathrm{L}, 6000 \mathrm{mg} / \mathrm{L}$. Then, the same procedure was practiced as mentioned in the experiment 1 .

\section{Chemical and Physical Analysis}

The treated water samples were analyzed for the parameters turbidity, electrical conductivity (EC) and $\mathrm{pH}$ at room temperature before and after treatments. EC and $\mathrm{pH}$ of the samples were measured using multi parameter analyzer. Turbidity was measured by turbidity meter.

\section{Statistical Analysis}

The experiments were conducted as a Full nested design to test the effect of coagulant types and concentration on the turbidity removal efficiency of water samples. Mean comparison of significant variables at $0.05 \alpha$ level were carried out using Turkey's Studentized Range Test (TSRT). All statistical analysis was performed using Statistical Analytical System (SAS software) at statistical significance $p<0.05$. All data were expressed as the mean \pm standard deviation.

\section{RESULTS AND DISCUSSION}

Figure 02 shows the results of the experiment 1 i.e. the variation of average residual turbidity of the synthetic turbid water samples treated by different concentrations $(50,60,70,80,90$, and $100 \mathrm{ppm}$ ) of PAC and natural coagulants (Moringa, Jack, Aloe, Arjun, and Clearing nut). The result of the experiment two is shown in figure 03 and it indicates the variation of average residual turbidity of the synthetic turbid water samples treated by different concentrations (1000, 2000,3000,4000,5000, and 6000ppm) of natural coagulants (Moringa, Jack, Aloe, Arjun, Clearing nut). As shown in figure 02, PAC at its lowest concentration could lower the turbidity to zero levels whereas natural coagulants even at comparatively higher concentration could not lower the turbidity considerably. However, natural coagulant at higher concentration (Figure 03), Moringa showed the considerable capability to lower the turbidity and it indicated residual turbidity $16.01( \pm 10.05) \mathrm{NTU}$ at $1000 \mathrm{ppm}$ concentration. When Moringa concentration increases, it seems that the turbidity removal capacity decreases slightly. A similar behavior was observed for the other natural coagulants. As shown in both figures, Arjun seeds exhibited the second lowest residual turbidity under 
all tested concentration levels. Relatively, Jack fruit seeds performed the least under the lower concentration and it behaved differently when the seed concentration increases. At the concentration around 4000 to $5000 \mathrm{ppm}$, Jack fruit also reached the residual turbidity levels achieved by the Arjun seeds.

The turbidity removal efficiencies of both experiments were calculated and all the data were statistically analyzed and mean values are shown in Table 01 and 2. PAC exhibited the highest turbidity removal efficiency of 99.3 ( \pm $0.04) \%$ and it reduced the initial turbidity of water from $102.84 \pm 10.39$ to $0.72 \pm 0.04$ NTU. PAC is being used as a coagulant probably due to this higher turbidity removal efficiency though it creates environmental issues. The second highest removal efficiency has achieved by the Moringa seeds and the removal efficiency was significantly lower $(p<0.05)$ than the PAC (Table 01). However, Moringar's ability of removing turbidity at the lower concentration was significantly higher than the other natural coagulant tested. Arjun seeds have achieved the second highest turbidity removal at lower and

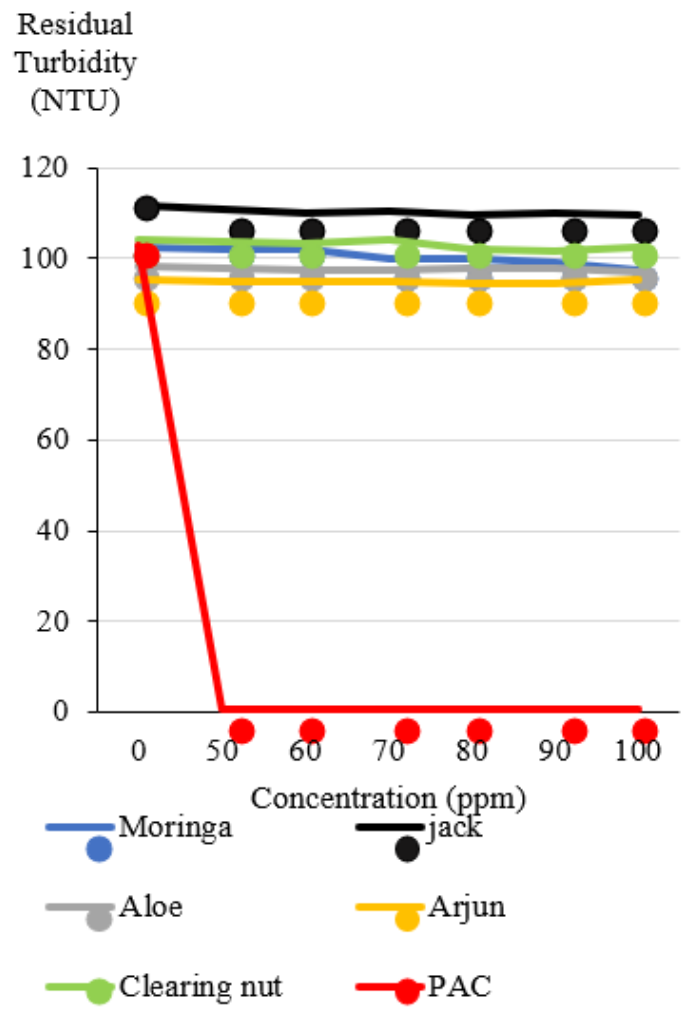

Figure 02: $\quad$ Residual Turbidity in water samples treated by different concentrations of natural coagulants and PAC (Results of experiment 1) higher concentrations (Figures 02 and 03).

When comparing only the turbidity removal efficiency among natural coagulants tested (Table 02), the highest turbidity removal efficiency, $84.84( \pm 8.89) \%$ was shown by Moringa which decreased the initial turbidity of water samples from $105.96( \pm 18.45)$ NTU to $16.01( \pm 10.05)$ NTU. Then Arjun and Aloe treated water have statistically the same turbidity removal efficiencies. Arjun and Aloe removed $42.62( \pm 6.71) \%$ and $34.90( \pm 6.03) \%$ of the initial turbidity of water samples respectively. Arjun treated water decreased the initial turbidity of water sample from $96.63( \pm 18.85)$ NTU to $55.61( \pm 12.54)$ NTU while Aloe decreased it from $103.66( \pm 27.90)$ NTU to $66.76( \pm 13.12)$ NTU. The lowest turbidity removal efficiencies were observed in Jack fruit and Clearing nut seed treated water as $18.23( \pm 9.29) \%$ and 30.46 $( \pm 23.71) \%$ respectively. Jack fruit decreased the initial turbidity of water sample from 90.8 $( \pm 20.01)$ NTU to $74.71( \pm 17.99)$ NTU whereas Clearing nut treated water decreased initial turbidity of water sample from $116.56( \pm 26.93)$ NTU to $76.07( \pm 18.52)$ NTU.

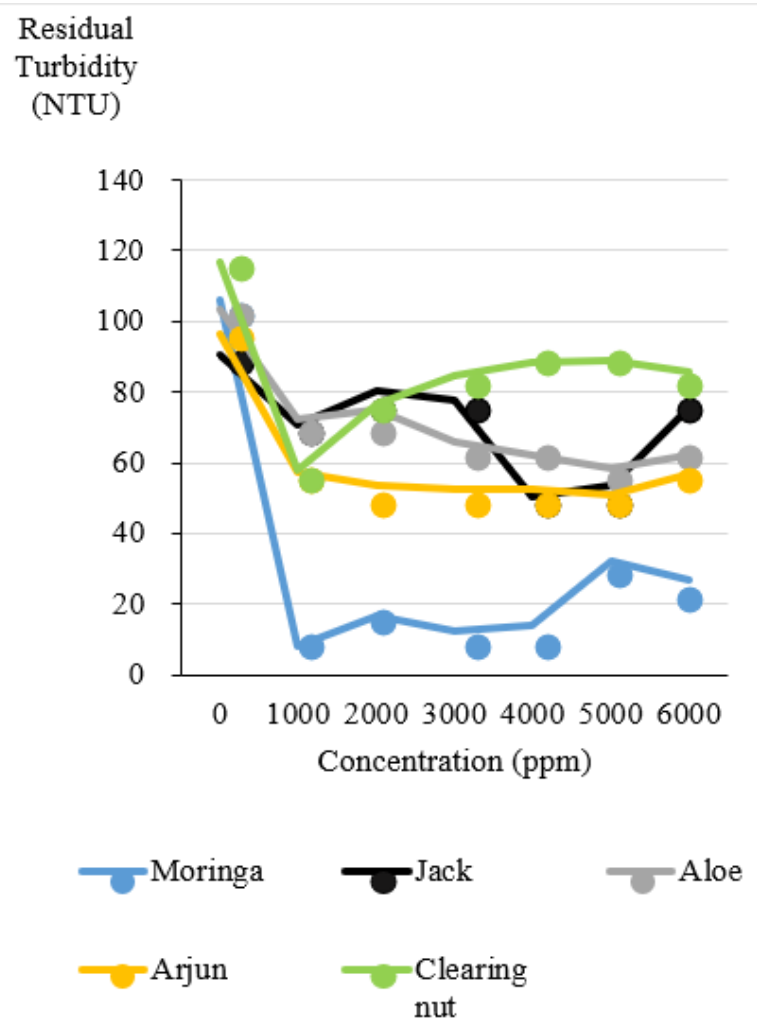

Figure 03: Residual Turbidity in synthetic turbid water samples at various concentrations of natural coagulants (Results of experiment 2) 


\begin{tabular}{cccc}
\hline Table 01: & \multicolumn{2}{c}{$\begin{array}{l}\text { Mean values of Initial turbidity, residual turbidity and turbidity removal efficiency of } \\
\text { treated water samples by PAC and natural coagulants }\end{array}$} \\
& Before treatment & \multicolumn{2}{c}{ After treatment } \\
\cline { 2 - 4 } Natural coagulant & Initial turbidity (NTU) & $\begin{array}{c}\text { Residual turbidity } \\
\text { (NTU) }\end{array}$ & $\begin{array}{c}\text { Turbidity removal } \\
\text { efficiency }(\%)\end{array}$ \\
\hline PAC & $102.84 \pm 10.39$ & $0.72 \pm 0.04$ & $99.3^{\mathrm{a}} \pm 0.04$ \\
Moringa & $105.96 \pm 18.45$ & $16.01^{\mathrm{c}} \pm 10.05$ & $84.84^{\mathrm{a}} \pm 8.89$ \\
Jack fruit & $90.8 \pm 20.01$ & $74.71^{\mathrm{a}} \pm 17.99$ & $18.23^{\mathrm{c}} \pm 9.29$ \\
Aloe & $103.66 \pm 27.90$ & $66.76^{\mathrm{b}} \pm 13.12$ & $34.90^{\mathrm{b}} \pm 6.03$ \\
Arjun & $96.63 \pm 18.85$ & $55.61^{\mathrm{b}} \pm 12.54$ & $42.62^{\mathrm{b}} \pm 6.71$ \\
Clearing nut & $116.56 \pm 26.93$ & $76.07^{\mathrm{a}} \pm 18.52$ & $30.46^{\mathrm{c}} \pm 23.71$ \\
\hline
\end{tabular}

Mean with the same letters in the same column are not significantly different

Table 02: Mean values of the Initial turbidity, residual turbidity and turbidity removal efficiency of treated water samples by natural coagulants (results of experiment 2)

\begin{tabular}{cccc}
\hline & Before treatment & \multicolumn{2}{c}{ After treatment } \\
\cline { 2 - 4 } Natural coagulant & Initial turbidity (NTU) & $\begin{array}{c}\text { Residual turbidity } \\
\text { (NTU) }\end{array}$ & $\begin{array}{c}\text { Turbidity removal } \\
\text { efficiency }(\%)\end{array}$ \\
\hline Moringa & $102.67 \pm 9.29$ & $99.98 \pm 2.30$ & $2.61^{\mathrm{b}} \pm 2.23$ \\
Arjun & $111.67 \pm 8.50$ & $110.30 \pm 0.77$ & $1.2^{\mathrm{c}} \pm 0.67$ \\
Aloe & $98.40 \pm 14.38$ & $97.47 \pm 0.38$ & $0.88^{\mathrm{c}} \pm 0.34$ \\
Jack fruit & $95.30 \pm 4.91$ & $95.11 \pm 0.31$ & $0.2^{\mathrm{d}} \pm 0.32$ \\
Clearing nut & $104.13 \pm 6.77$ & $103.57 \pm 0.75$ & $0.53^{\mathrm{d}} \pm 0.70$ \\
\hline
\end{tabular}

Mean with the same letters in the same column are not significantly different

Moringa collected from dry zone Anuradhapura performed well as a coagulant both in lower and higher concentrations compared to other natural coagulants taken into the study. Mangale et al. (2012) showed that Moringa seed powder collected from Kolhapur area in India has a turbidity removal efficiency of $75.32 \% \pm 5.15 \%$. In the present study, Moringa seeds collected from dry zone, Sri Lanka exhibited superior results than that of Mangale et al. (2012) where it showed a turbidity removal efficiency of $84.84( \pm 8.89) \%$. The presence of water-soluble cationic proteins in the seeds of Moringa acts as a coagulant which caused the adsorption, charge neutralization and interparticle bridging affecting the coagulation mechanism (Nadabigengesere et al. (1995); Amagloh and Benang ,2009).

At high concentration of coagulant, coagulant concentration is higher than that of the turbid mud particles, coagulant molecules may not have enough mud particles to bind and precipitate. That may result in dispersion of the rest of the coagulants molecules in the water which will cause a slight increase in turbidity or decrease in turbidity reduction efficiency at higher concentration of natural coagulants (Figure 03). 


\section{Variation of $\mathrm{pH}$}

Average $\mathrm{pH}$ of water samples treated with the natural coagulant and also PAC changed its $\mathrm{pH}$ compared to its initial stage. PAC tends to increase the acidity levels of the samples with the increase of concentration. It is observed that $\mathrm{pH}$ of water treated by all natural coagulant at lower concentration increases slightly (Figure 04b). Jack fruit seed increases the acidity levels of the samples especially at a higher concentration of the coagulant. However, other natural coagulants do not show any drastic changes of the $\mathrm{pH}$ when the concentration of the coagulant increases. As an average, Moringa, Clearing nut and Arjun treated water exhibited statistically significantly higher $\mathrm{pH}$ than Jack fruit seeds and Aloe treated water (Table 03). It is suggested that when there are basic amino acids present in protein that can accept protons from water, it would release hydroxyl groups to the water. This would be a fact to increase the $\mathrm{pH}$ of the water treated with Moringa, Arjun, Clearing nut, and Aloe which make the water more basic compared with the 0 ppm level (Amagloh and Benang, 2009). According to Ocloo et al., 2010 the $\mathrm{pH}$ and the titraTable 0acidity (as lactic acid) of the jack fruit seed flour are 5.78 and $1.12 \%$ respectively. The amount of acidity contained in the Jack fruit seed may be a factor to lower the $\mathrm{pH}$ of the treated water.

\section{Electrical Conductivity (EC)}

Figure 05 indicates the variation of EC of different concentrations of natural coagulant and PAC. Figure 05 a graph shows an abrupt increase of the EC in PAC treated water when the PAC concentration increases. However, water treated by natural coagulant at this lower concentration, there was no considerable variation of $\mathrm{EC}$ with the initial EC values and the EC varied only 300 to $310 \mu \mathrm{s} / \mathrm{cm}$. However, when the natural coagulant concentration increases, there is a considerable increase of EC of Moringa and Jack fruit. Results imply that PAC release more electrolyte to the water when the concentration increases. Similarly, Jack fruit and Moringa influence to increase the dissolved ions in the water parallel to increased concentration of the same coagulants. When the concentration of Aloe, Arjun and Clearing nut increases, respective EC of water showed a slight decrease.
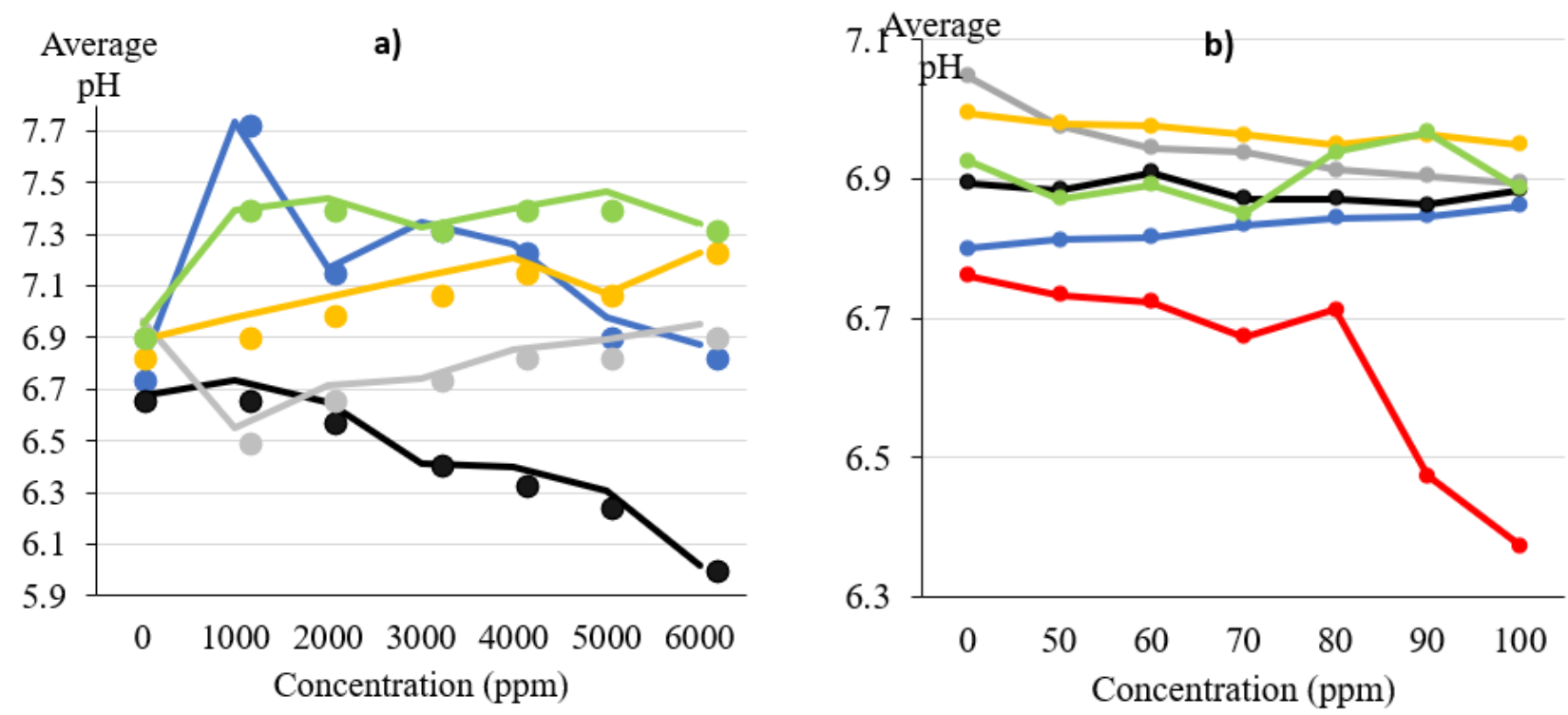

Figure 04: Variations of $\mathrm{pH}$ of water samples treated by (a) : different concentrations of natural coagulant only and (b) natural coagulant with the PAC 


\section{Table 03: Mean values of $\mathrm{pH}$ and $\mathrm{EC}$ of water samples treated with the natural coagulant}

\begin{tabular}{ccc}
\hline Natural coagulant & $\mathrm{pH}$ & $\mathrm{EC}(\mu \mathrm{s} / \mathrm{cm})$ \\
\hline Moringa & $7.31^{\mathrm{a}} \pm 0.42$ & $456.22^{\mathrm{a}} \pm 74.72$ \\
Jack fruit & $6.38^{\mathrm{c}} \pm 0.31$ & $404.52^{\mathrm{b}} \pm 60.72$ \\
Aloe & $6.74^{\mathrm{b}} \pm 0.33$ & $355.92^{\mathrm{c}} \pm 29.38$ \\
Arjun & $7.11^{\mathrm{a}} \pm 0.15$ & $327.08^{\mathrm{c}} \pm 9.33$ \\
Clearing nut & $7.35^{\mathrm{a}} \pm 0.28$ & $353.48^{\mathrm{c}} \pm 18.80$ \\
\hline
\end{tabular}

Mean with the same letters in the same column are not significantly different

EC

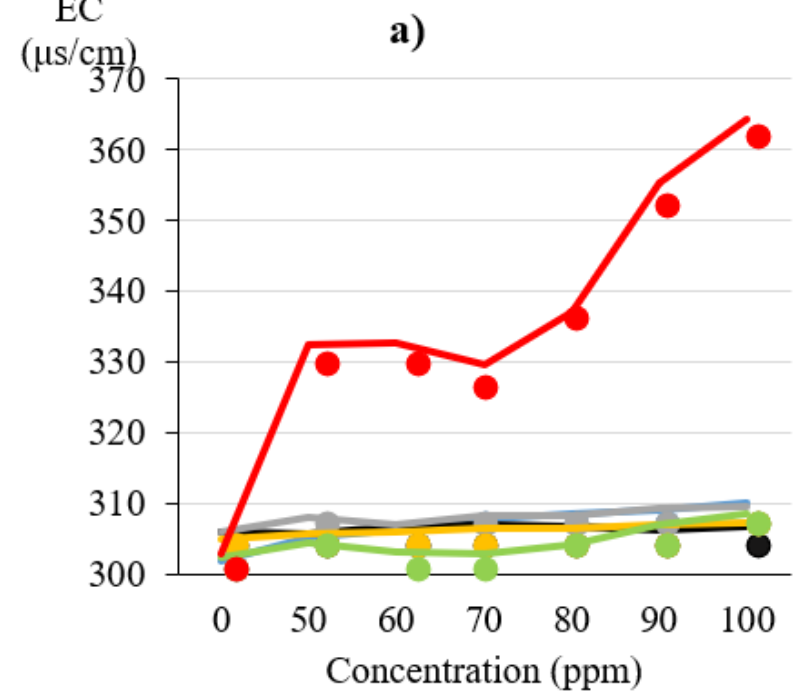

EC

$(\mu \mathrm{s} / \mathrm{cm})$

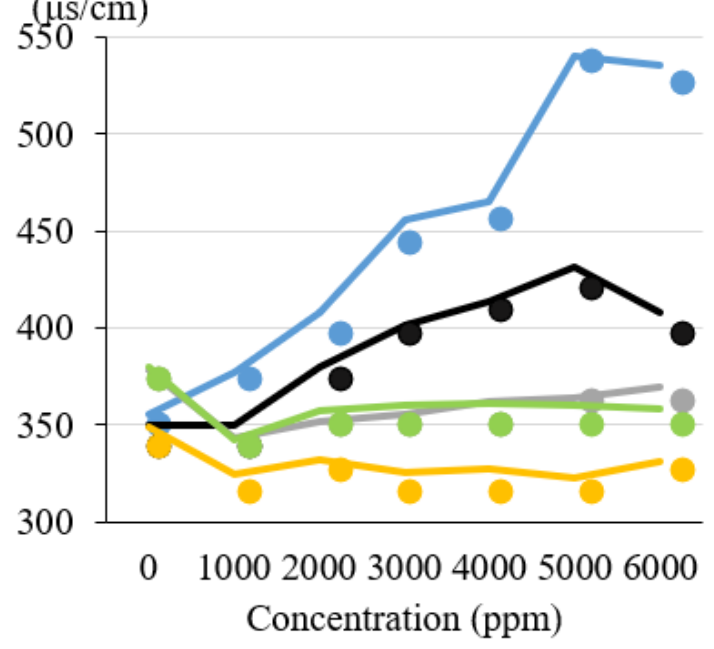

Moringa
Aloe vera
Clearing nut b)

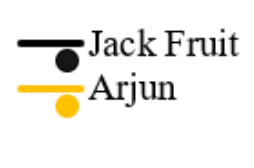

Figure 05: Variation of EC with the different concentration of (a) natural coagulant and PAC (b) natural coagulants onlyss

Considering the mean values, EC of Moringa treated water showed significant higher values than other natural coagulants while second highest EC values are recorded in Jack fruit seed treated water. Aloe, Arjun and Clearing nut treated turbid water indicated statistically the same EC values.

\section{CONCLUSIONS}

Among the natural coagulants tested, Moringa seeds showed the highest capability of removing turbidity of the water with an efficiency of $84.84( \pm 8.89) \%$. Arjun and Aloe demonstrated turbidity removal efficiency of $42.6( \pm 6.71)$ $\%$, and $34.9( \pm 6.03) \%$ respectively and it was significantly $(\mathrm{P}<0.05)$ higher than those of Jack fruit $18.2( \pm 9.3) \%$ and Clearing nut $30.4( \pm$ 23.7) $\%$. The results concluded that there are significant differences $(\mathrm{P}<0.05)$ among selected natural coagulants on removing the turbidity of water. However, none of the natural coagulants could achieve a turbidity removal efficiency to the level required for drinking water standards which was done by the PAC having the turbidity 
removal efficiency of $99.3( \pm 0.04) \%$. However, PAC increase the acidity of water and EC considerably than the natural coagulant tested.

\section{SUGGESTIONS}

Further studies are recommended combining these natural coagulants and PAC to test the efficiency of the turbidity reduction of the water. It is needed to utilize different scales of turbidity levels and coagulant concentrations to test the efficiency of the natural coagulants. Further, it is necessary to find out more locally available plant materials in treating turbid water. Due to non-availability of fresh Clearing nut at the time of experiment, study collected them from an Ayurveda shop in Anuradhapura. It would give different results if pure seeds of Clearing nut were tested for removing turbidity of water.

\section{Data availability statement}

The datasets generated during and/or analyzed during the current study are available from the corresponding author on reasonable request.

There is no conflict of interest among authors.

\section{REFERENCES}

Abeysingha, N.S., Dassanayake, K.B. \& Weerarathna, C.S. (2018). Will restoration of ecological functions of tank cascade system contribute to reduce CKDu in Sri Lanka? a Review. Journal of environment management and sustainable development, 7 (3), pp.60-81 https://doi.org/10.5296/ emsd. v7i3.13129.J.

Amagloh,F.K. and Benang, A.(2009).Effectiveness of Moringa oleifera seed as coagulant for water purification.African Journal of Agricultural Research,4(1), pp.119-123

Aneesu, R., Aswathy, R., Ranjitha, O., R., Suranya, T., Jency, N. (2018). Efficiency of Jackfruit Seed Powder as a Natural Coagulant. International Research Journal of Engineering and Technology,5(3),pp.3060-3062

Arasaretnam, S. and Keerthanan, S.(2018). Plant Seeds as Biosorbents for the Purification of Water. Journal of Modern Chemistry \& Chemical Technology, 9(2), pp.30-39

Asrafuzzaman, M., Fakhruddin, A. N. M., Hossain,A.(2011). Reduction of Turbidity of Water Using Locally Available Natural Coagulants.International Scholary Research Network, pp.1-7 https:// doi.org/10.5402/2011/632189.

Bratby, J.(1980).Coagulation and flocculation: with an emphasis on water and wastewater treatment, $3^{\text {rd }}$ edn.Uplands press ltd,England,pp.538 https://doi.org/10.1016/0300-9467(81)80062-7.

Dezuane,J.(1997). Handbook of Drinking Water Quality,2 $2^{\text {nd }}$ edn.John Wiley \& Sons,Newyork, pp.592

Dharmasinghe, S. (2017). Poly aluminium chloride as an alternative to Alum as a coagulant in water treatment. Msc. Thesis, University of Moratuwa, Sri Lanka.

Flaten, T. P. (2001). Aluminium as a risk factor in Alzheimer's disease with emphasis on drinking water. Brain Res Bull, 55(2), pp.187-196

Jahn,S.A.A.(1988). Using Moringa Seeds as Coagulants in Developing Countries.American Water Works Association, 80(6),pp.43-50 
Jayaram, K., Murthy, I.Y.L.N., Lalhruaitluangaa, H. and Prasada, M.N.V. (2009) Biosorption of lead from aqueous solution by seed powder of Strychnos potatorum L.. Colloids and Surfaces B: Biointerfaces, 71(2), pp.248-254.https://doi.org/10.1016/j.colsurfb.2009.02.016.

Kurniawan,S.B., Abdullah,S.R.S., Imron, M.F., Said, N.S.M., Ismail,N.I., Hasan, H.A., Othman, A.R. and Purwanti, I.F. ( 2020) Challenges and Opportunities of Biocoagulant/Bioflocculant Application for Drinking Water and Wastewater Treatment and Its Potential for Sludge Recovery. International journal of Environemntal REsearch and Public health, https://doi.org/10.3390/ ijerph17249312

Mangale, S. M.,Chonde,S.G.,Jadhav,A.S. and Raut,P.D.(2012).Study of Moringa oleifera ( Drumstick ) seed as natural Absorbent and Antimicrobial agent for River water treatment.Journal of Natural Product and Plant Resource, 2(1),pp.89-100

Munavalli, G. R. (2017).Use of Aloe Vera as Coagulant aid in Turbidity Removal. International Journal of Engineering Research and Technology, 10(1),pp.314-317

Munoz,O.M.,Leal,X., Quitral,V. and Cardemil,L.(2015). Extraction Characterization and Properties of the Gel of Aloe Vera (Aloe barbadensis Miller) Cultivated in Chile. Medicinal \& Aromatic Plants Extraction, 4(3),pp.199, https://doi.org/10.4172/2167-0412.1000199

Ocloo,F.C.K.,Bansa,D.,Boatin,R.,Adom,T. and Agbemavor,W.S.(2010). Physico-chemical, functional and pasting characteristics of flour produced from Jackfruits (Artocarpus heterophyllus) seeds. Agriculture and biology journal of North America,1(5), pp.903-908

Niquette, P., Monette, F., Azzouz, A. and Hausler, R. (2004). Impacts of Substituting AluminumBased Coagulants in Drinking Water Treatment, Water Quality Research Journal of Canada, 39(3), pp.303-310

Rao, R. A. K., Khatoon, A. and Ashfaq, A. (2016).Application of Terminalia arjuna as potential adsorbent for the removal of $\mathrm{Pb}(\mathrm{II})$ from aqueous solution: thermodynamics, kinetics and process design. Desalination and Water Treatment, 57(38),pp.17808-17825 https://doi.org/10. 1080/19443994.2015.1087878.

Ravikumar,K. and Sheeja,A.K.(2013).Fluoride Removal from Water using Moringa oleifera Seed Coagulation and Double Filtration.International Journal of Scientific \& Engineering Research, 4(8), pp.1-5

Ravindara, M.,Kumarrapperuma,S.R., Ekneligoda,T.C. and Fernando,D.I.(2013).The effectiveness of local plants as natural coagulants in treating turbid water in Sri Lanka.Journal of Chemical Information and Modeling, 53(9), pp.1689-1699.https://doi.org/10.1017/ CBO9781107415324.004.

Yongabi, K. (2010).Biocoagulants for water and waste water purification: a review, International review of chemical engineering, 2(3), pp.444-458 